\title{
Precancerous Cervical Lesion Among Women in Public Hospitals of Addis Ababa, Ethiopia
}

\author{
Tesfay Temesgen ${ }^{1, *}$, Girmay Adhena ${ }^{2,}$, Zerihun Figa $^{1}$ \\ ${ }^{1}$ Department of Midwifery, College of Health Science, Dilla University, Dilla, Ethiopia \\ ${ }^{2}$ Department of Reproductive Health, Tigray Regional Health Bureau, Tigray, Ethiopia
}

Email address:

girmayrh@gmail.com (G. Adhena)

*Corresponding author

\section{To cite this article:}

Tesfay Temesgen, Girmay Adhena, Zerihun Figa. Precancerous Cervical Lesion Among Women in Public Hospitals of Addis Ababa, Ethiopia. Cancer Research Journal. Vol. 8, No. 4, 2020, pp. 94-99. doi: 10.11648/j.crj.20200804.15

Received: September 1, 2020; Accepted: September 19, 2020; Published: December 16, 2020

\begin{abstract}
Background: Cervical cancer is one of the leading causes of death among women in the world and particularly in Africa. Countries of the glob adopted proven the importance of precancerous lesion screening. However, cervical cancer remains one of the leading causes of cancer morbidity and mortality in sub-Saharan Africa including Ethiopia. This study assessed the prevalence and associated factors of precancerous cervical lesions among women screened at public hospitals in Addis Ababa, Ethiopia. Methods: Institutional based cross-sectional study was conducted among 234 women screened in five public hospitals of Addis Ababa selected by systematic sampling technique. Data were collected by interview using a structured and pre-tested questionnaire. The association of the variable was done by using binary and multiple logistic regressions and a $95 \%$ confidence interval were computed to determine the level of significance. Variable with P-value $<0.05$ was considered as statistically significant. Results: The prevalence of cervical precancerous lesion was $14.1 \%$ [(95\% CI: $(9.4$, 18.8)]. Having multiple sexual partners $((\mathrm{AOR}=4.17,95 \% \mathrm{CI}:(1.3,13.36)]$, Being human immune virus positive (HIV) [AOR $=8.16,95 \%$ CI: $(2.08,32.09)]$, early initiation of sex (before 18 years old) $[\mathrm{AOR}=2.34,95 \% \mathrm{CI}$ : $(1.13,5.7)]$, having history of sexual transmitted disease $[\mathrm{AOR}=9.97,95 \% \mathrm{CI}:(2.98,33.4)$ and, having a husband with history of sexual transmitted disease $[\mathrm{AOR}=4.07,95 \% \mathrm{CI}:(1.35,12.3)]$ were factors significantly associate with the risk of being positive with precancerous cervical lesion. Conclusion: A significant number of women were positive for visual inspection with acetic acid screening (precancerous cervical lesion). Enhancing early cervical cancer screening and addressing community awareness on comprehensive sexual and reproductive health issues tailored to age and culture and early treatment of sexually transmitted diseases are important measures to decrease the problem.
\end{abstract}

Keywords: Precancerous, Cervical Lesion, Visual Inspection of Acetic Acid, Addis Ababa, Ethiopia

\section{Background}

Cervical cancer is cancer arising from the cervix, in which the cells of the cervix become abnormal and start to grow uncontrollably, forming a tumor [1]. Precancerous conditions of the cervix are changes to cervical cells that make them more likely to develop into cancer and happen in an area called the transformation zone, where columnar cells are constantly being changed into squamous cells. About $90 \%$ of cervical cancer cases are squamous cell carcinomas, $10 \%$ are adenocarcinoma, and a small number are other types [2].

The early stages of cervical cancer may be completely free of symptoms. Vaginal bleeding, contact bleeding (one most common form being bleeding after sexual intercourse), vaginal mass rarely may indicate the presence of malignancy [3]. Human papillomavirus infection causes more than $90 \%$ of cases and human papillomavirus vaccines prevent up to $90 \%$ of cervical cancer. Cervical cancer screening using the pap test or acetic acid can identify precancerous changes when treated can prevent the development of cancer [4].

Surgical intervention may have better outcomes than radiological approaches [5]. Checking the cervix by the Papanicolaou's (pap test), for cervical cancer has dramatically reduced the number of cases and mortality from cervical cancer in developed countries. Pap test screening every three 
to five years with appropriate follow-up can reduce cervical cancer incidence up to $80 \%$ [6].

Cervical cancer is the fourth frequent cancer in women with an estimated 570,000 new cases in 2018 representing $6.6 \%$ of all cancers. Approximately $90 \%$ of deaths from cervical cancer occurred in low- and middle-income countries [7]. About $70 \%$ of cervical cancers occur in developing and low-income countries, and it is one of the most common causes of cancer deaths [8]. Cervical cancer incidence rates in sub-Sahara Africa (SSA) are the highest in the world and the disease is the most common cause of cancer death among women in the region. It is expected that due to lack of access to appropriate prevention services and the concomitant HIV/AIDS epidemic, cervical cancer incidence and mortality rates in sub-Saharan Africa will rise over the next 20 years [9].

In sub-Saharan Africa, cervical cancer accounts for $22.2 \%$ of all cancers in women and it is also the most common cause of cancer death [10]. About $60-75 \%$ of women in subSaharan Africa who develop cervical cancer live in rural areas. Many of these women go untreated, mostly due to a lack of access to health care. Women in SSA lose more years to cervical cancer than to any other type of cancer. Unfortunately, it affects them at a time of life when they are critical to the social and economic stability of their families. Only in very few African countries have functional registries and record-keeping is minimal or non-existent. A mortality rate of 35 per 100,000 is reported in Eastern Africa [11]. The reported mortality rates in developed countries with successful screening programs seldom exceed 5 per 100,000 women [12]. The incidence and mortality rate of the disease in Africa is high [13].

The problem is top prevalent and fatal in Africa especially in east Africa including Ethiopia. A study conducted in Jimma $12.9 \%$ [14] and Yirgalem $16.5 \%$ of screened clients had a visual inspection with acetic acid positive result [15]. Despite the importance of screening, a high incidence of cervical cancer is still a big problem and a major cause of morbidity and mortality of women in Africa, particularly in Ethiopia. There are few studies that existed in Ethiopia but these were conducted using secondary data. Therefore, this study was designed to assess precancerous cervical lesion in public hospitals of Addis Ababa using primary data.

\section{Methods}

\subsection{Study Area and Period}

The study was conducted in Addis Ababa, the capital city of Ethiopia. According to the 2007 demographic survey, the city has a total population of 4 million. There were 12 public hospitals that providing health care services for the community. The study was conducted in five selected public Hospitals of Addis Ababa (Zewditu Memorial Hospital, St. Peter $\mathrm{Tb}$ Specialized Hospital, Tirunesh Beijing Hospital, Yekatit 12 Hospital, and Gandi Hospital). The study was conducted from May 1- June 30, 2019.

\subsection{Study Design and Population}

Institutional based cross-sectional study was conducted. All women aged 30 years old and above in Adis Ababa were considered the source population. All women who came for screening to the selected public hospitals were considered as a study population.

\subsection{Sample Size Calculations and Sampling Procedures}

The sample size was determined by using single population proportion formula $\left(n=(\mathrm{Za} / 2)^{2} p(1-p) / d^{2}\right)$, where $\mathrm{z}$ is with $95 \%$ confidence interval, marginal error (d) of $5 \%$ and the prevalence of precancerous cervical lesion (p) $16.5 \%$ similar study conducted in Yirgalem hospital [15] and became 212 but by adding the non-response rate of $10 \%$ $(212+212 * 0.01)$ then the final sample size becomes 234 . The participants were selected by using a systematic random sampling technique every second woman $\left(\mathrm{K}^{\text {th }}=2\right)$ from each selected hospital. The first study unit for each site was selected by the lottery method then every second participant was taken until the sample size met.

\subsection{Data Collection Tool and Procedures}

Data were collected by face to face interview using a structured questionnaire. The questionnaire was designed carefully and prepared in the English language first and then was translated into Amharic by language experts and again the Amharic version was translated back to English by other persons to make it consistent. Finally, the Amharic version was used to collect data. The questionnaire was pretested before actual data collection time in $10 \%$ of the sample size in St. Paul specialized hospital which is out of the study site. Data were collected by five-degree holder Midwives. Two Master holders and the principal investigators supervised the data collection processes. Data collectors and supervisors were trained for two days on interviewing techniques, purpose, and ethical issues. The collected data were cleaned and cross-checked for consistency daily and double data entry was done.

\subsection{Operational Definitions}

Multiple sexual partners: Woman who has more than onelifetime sexual partners [16].

Precancerous cervical lesion: An intraepithelial lesion, which is abnormal in the cells of a cervix which can grow to cancer. After the application of acetic acid to the cervical organs by trained professionals white lesions become visible [2].

Visual inspection of acetic acid: Visual examination of the cervix by applying $3-5 \%$ of acetic acid.

Early sexual intercourse: A woman who had sexual intercourse before 18 years old [16].

\subsection{Data Processing and Analysis}

The collected data were coded, entered, and cleaned using Epi data 4.4.2.1 and then exported and analyzed using SPSS 
version 24. Descriptive statistical analyses such as simple frequencies, percentages, measures of central tendency, and measure of variability were used to describe the characteristics of participants. The information was presented using narratives, tables, and figures. The association of the independent variables and the dependent variable was done by using binary and multiple logistic regressions. The odds ratio with a $95 \%$ confidence interval was computed to show strength and direction. Variables with $p$-value $<0.25$ on binary logistic regression were transferred to multiple logistic regression. Co-linearity test was carried out to see the correlation between independent variables using the standard error. A Hosmer-Lemeshow and Omnibus tests were conducted to test model goodness of fit. Finally, variables with $\mathrm{p}$-value $<0.05$ in the final model (multivariate analysis) were considered as statistically significant.

\subsection{Ethical Approval}

Ethical clearance was secured from the research board of Addis Ababa University. A letter of permission was given to each selected public hospitals. A formal letter was written to each selected public hospital and informed, written, voluntary, and signed consent was obtained from each participant. The participant has informed about the purpose of the study and kept their confidentiality by not writing their name in the paper. Participants were informed participating in this study is up to their interest and also they can stop the interview at any time which is not comforting for them.

\section{Results}

\subsection{Socio-demographic Characteristics of Participants}

A total of 234 women was interviewed making a response rate of 100 percent. More than one-third (37\%) of participants were in the age group of 30-35 years old. The majority of the participants, $152(65 \%)$ were orthodox Christian in their religion. Most of the women, $189(80.8 \%)$ were married in their relationship status and about half (53.4\%) of the participants were government employed in their occupational status. Regarding the educational level of participants, 102 (43.6\%) were learned higher education, and about $63(26.9 \%)$ were learned up to secondary school. About 228 (97.4\%) participants were urban residents (Table 1).

Table 1. Sociodemographic characteristics among precancerous cervical lesion screened women in public hospitals of Addis Ababa, Ethiopia, 2019 $(N=234)$.

\begin{tabular}{llll}
\hline Variable & Categories & Frequency & Percent \\
\hline \multirow{3}{*}{ Age (Year) } & $30-35$ & 86 & 37 \\
& $36-40$ & 71 & 30 \\
& $41-45$ & 47 & 20 \\
& $\geq 46$ & 30 & 13 \\
\multirow{4}{*}{ Marital status } & Single & 2 & 0.9 \\
& Married & 189 & 80.8 \\
& Widowed & 24 & 10.3 \\
\multirow{3}{*}{ Religion } & Divorced & 19 & 8 \\
& Orthodox & 152 & 65 \\
& Muslim & 43 & 18.4 \\
\hline
\end{tabular}

\begin{tabular}{llll}
\hline Variable & Categories & Frequency & Percent \\
\hline & Protestant & 34 & 14.5 \\
& Catholic & 5 & 2.1 \\
& Unable to read and write & 22 & 9.4 \\
& Can read and write & 23 & 9.8 \\
Educational level & Primary school & 24 & 10.3 \\
& Secondary school & 63 & 26.9 \\
& Higher education & 102 & 43.6 \\
& Housewife & 44 & 18.8 \\
& Merchant & 32 & 13.7 \\
Occupational level & Daily laborer & 4 & 1.7 \\
& Government employee & 125 & 53.4 \\
& Nongovernmental & 29 & 12.4 \\
& employee & 6 & 2.6 \\
Residence & Rural & 228 & 97.4 \\
\hline
\end{tabular}

\subsection{Reproductive Health and Sexual Behavior Related Characteristics}

Of the total screened women, $122(52.1 \%)$ were used family planning methods. Out of this number, the implant (21.4\%), injectable (9.8\%), Oral pill (3.4\%), IUCD (17.5\%) were used. Nearly half, 112 (47.9\%) of participants have not used any family planning methods. About $47 \%$ and $49 \%$ of participants began menarche between $13-14$ and $\geq 15$ years old respectively. About $30.8 \%$ begin early sexual initiation ( $<18$ years old) and $83.3 \%$ of the participants reported that they had never used a condom during sexual intercourse. More than one-fourth of women's and near one-fifth of husbands of participants had history STD. The majority, 198 $(84.8 \%)$ of women had given birth at the age of 18 and above. Twelve $(5.1 \%)$ women reported that they have a family history of cervical cancer. About $12 \%$ of women were HIV positive, $62 \%$ of women and about $19.5 \%$ of husbands of participants had two and above sexual partners in their lifetime. Only twenty-three $(9.8 \%)$ women were screened by VIA before this test. About $23(9.8 \%)$ women were married early (before 18 years old) (Table 2 ).

Table 2. Reproductive health and sexual behavior related characteristics among precancerous cervical lesion screened women in public hospitals of Addis Ababa, Ethiopia, 2019 (N=234).

\begin{tabular}{|c|c|c|c|}
\hline Variables & Categories & Frequency & Percentage \\
\hline \multirow{5}{*}{$\begin{array}{l}\text { The contraceptive } \\
\text { method she used }\end{array}$} & Oral contraceptive pills & 8 & 3.4 \\
\hline & Injectable & 23 & 9.8 \\
\hline & Implant & 50 & 21.4 \\
\hline & IUCD & 41 & 17.5 \\
\hline & No contraceptive used & 112 & 47.9 \\
\hline \multirow{3}{*}{$\begin{array}{l}\text { Age at menarche } \\
\text { (Year) }\end{array}$} & $<12$ & 9 & 3.9 \\
\hline & $13-14$ & 110 & 47.0 \\
\hline & $\geq 15$ & 115 & 49.1 \\
\hline \multirow{4}{*}{$\begin{array}{l}\text { Age at first birth } \\
\text { (Year) } \\
\text { Is there a family } \\
\text { history of cervical } \\
\text { cancer }\end{array}$} & $<18$ & 10 & 4.3 \\
\hline & $\geq 18$ & 198 & 84.6 \\
\hline & Yes & 12 & 5.1 \\
\hline & No & 222 & 94.9 \\
\hline \multirow{2}{*}{$\begin{array}{l}\text { Age at first sexual } \\
\text { intercourse (Years) }\end{array}$} & $<18$ & 73 & 30.8 \\
\hline & $\geq 18$ & 161 & 69.2 \\
\hline \multirow{4}{*}{$\begin{array}{l}\text { Age at the first } \\
\text { marriage (Year) } \\
\text { Condom use during } \\
\text { sexual intercourse }\end{array}$} & $<18$ & 23 & 9.8 \\
\hline & $\geq 18$ & 211 & 90.2 \\
\hline & Always & 3 & 1.3 \\
\hline & Sometimes & 36 & 15.4 \\
\hline
\end{tabular}




\begin{tabular}{|c|c|c|c|}
\hline Variables & Categories & Frequency & Percentage \\
\hline \multirow{3}{*}{$\begin{array}{l}\text { History of STD } \\
\text { (Women) }\end{array}$} & Never & 195 & 83.3 \\
\hline & Yes & 61 & 26.1 \\
\hline & No & 173 & 73.9 \\
\hline \multirow{2}{*}{$\begin{array}{l}\text { Husband history of } \\
\text { STD }\end{array}$} & Yes & 45 & 19.2 \\
\hline & No & 189 & 80.8 \\
\hline \multirow{4}{*}{$\begin{array}{l}\text { HIV status } \\
\text { (Women) } \\
\text { Lifetime sexual } \\
\text { partner }\end{array}$} & Positive & 28 & 12 \\
\hline & Negative & 206 & 88 \\
\hline & only one & 89 & 38 \\
\hline & Two and above & 145 & 62 \\
\hline \multirow{3}{*}{$\begin{array}{l}\text { Husband's lifetime } \\
\text { sexual partner }\end{array}$} & No & 140 & 59.8 \\
\hline & Only one & 48 & 20.5 \\
\hline & $\geq 2$ & 46 & 19.7 \\
\hline
\end{tabular}

\subsection{Prevalence of Precancerous Cervical Lesion}

Out of the total 234 participated women who screened on the five public hospitals of Addis Ababa, about 14.1\% (95\% CI: $(9.4,18.8)$ were positive for the VIA test (had precancerous cervical lesion) (figure 1).

\subsection{Factors associated with precancerous cervical lesion}

In the binary logistic regression analysis age, age at first sexual intercourse, age at first marriage, HIV status, history of STD, husbands' history of STD, lifetime sexual partner, and husbands' lifetime sexual partner were significantly associated factors with the precancerous cervical lesion. But, in the final model (multivariable logistic regression analysis) HIV status, age at first sexual intercourse, history of STD, husbands' history of STD, lifetime sexual partner status remained the main significant factors associated with the precancerous cervical lesion (Table 3).

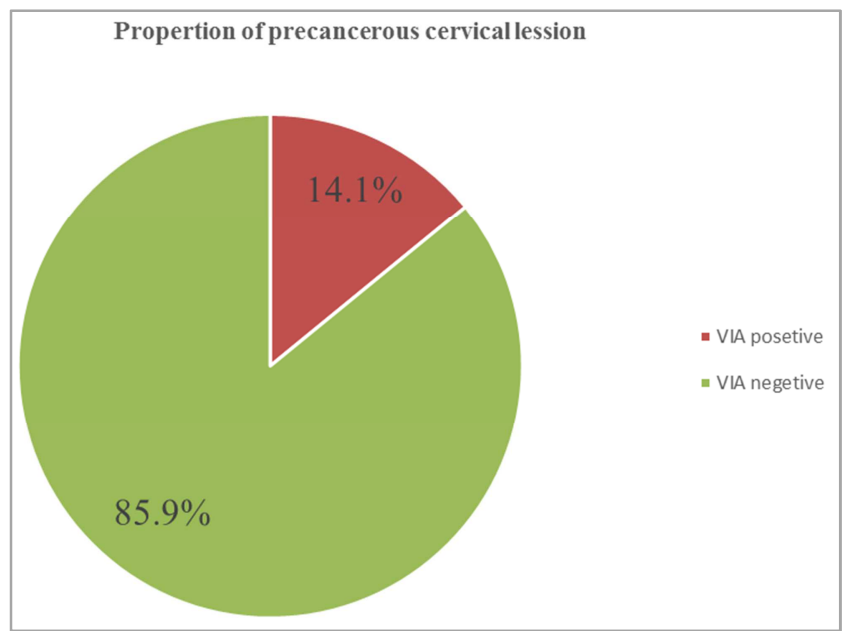

Figure 1. Proportion of precancerous cervical lesion among screened women in public hospitals of Adis Ababa, Ethiopia, 2019 (N=234).

Table 3. Factors independently associated with precancerous cervical lesion among screened women in public hospitals of Addis Ababa, Ethiopia, 2019 $(N=234)$.

\begin{tabular}{|c|c|c|c|c|}
\hline Characteristics & VIA +ve & VIA-ve & COR $(95 \%$ CI) & $\operatorname{AOR}(95 \%$ CI $)$ \\
\hline \multicolumn{5}{|l|}{ Age (Year) } \\
\hline $30-35$ & 5 & 81 & 1 & 1 \\
\hline $36-40$ & 6 & 65 & $0.669(0.195,2.290)$ & $0.667(0.377,1.181)$ \\
\hline $41-45$ & 10 & 37 & $0.228(0.073,0.715)$ & $0.221(0.121,1.02)$ \\
\hline$\geq 46$ & 12 & 18 & $0.093(0.029,0.296)$ & $0.087(0.023,1.04)$ \\
\hline \multicolumn{5}{|l|}{ Age at first sex } \\
\hline$<18$ & 17 & 56 & $2.75(1.3,5.8)$ & $2.34(1.13,5.7)^{*}$ \\
\hline \multicolumn{5}{|c|}{ Age at first marriage } \\
\hline$<18$ & 10 & 13 & $6.28(2.47,15.95)$ & $2.092(0.377,11.60)$ \\
\hline$\geq 18$ & 23 & 188 & 1 & 1 \\
\hline \multicolumn{5}{|l|}{ History of STD } \\
\hline Yes & 24 & 37 & $11.82(5.07,27.51)$ & $9.97(2.977,33.42)^{*}$ \\
\hline No & 9 & 164 & 1 & 1 \\
\hline \multicolumn{5}{|c|}{ History of Husband STD } \\
\hline No & 12 & 177 & 1 & 1 \\
\hline \multicolumn{5}{|l|}{ HIV status } \\
\hline Positive & 15 & 13 & $12(4.834,29.468)$ & $8.16(2.075,32.09)^{* *}$ \\
\hline Negative & 18 & 188 & 1 & 1 \\
\hline \multicolumn{5}{|c|}{ Lifetime sexual partner } \\
\hline One & 20 & 69 & 1 & 1 \\
\hline Two and above & 13 & 132 & $2.94(1.340,6.017)$ & $4.17(1.30,13.36)^{*}$ \\
\hline \multicolumn{5}{|c|}{ Husband's other lifetime sexual partner } \\
\hline No & 9 & 131 & 1 & 1 \\
\hline One & 8 & 40 & $0.344(0.124,0.949)$ & $0.553(0.271,1.132)$ \\
\hline Two and above & 16 & 30 & $0.129(0.052,0.319)$ & $0.11(0.61,1.01)$ \\
\hline
\end{tabular}

$*=\mathrm{p}$ value $<0.05 ; * *=\mathrm{p}$ value $<0.01 \mathrm{CI}=$ confidence interval; $\mathrm{AOR}=$ adjusted odds ratio; $\mathrm{COR}=\mathrm{Crud}$ odds ratio.

\section{Discussion}

The prevalence of precancerous cervical lesions was 14.1\% (95\% CI: 9.4, 18.8). Being HIV positive, early initiation of sexual intercourse, having multiple sexual partners, history of STD, and husband's history of STD were significantly associated factors with the precancerous cervical lesion. 
The prevalence in this study $(14.1 \%)$ is in line with the studies done in Ethiopia, such as in Yirgalem (16.5\%) [15] and in Jimma (12.9\%) [14]. This similarity might be due to the geographical, lifestyle, and cultural similarities that shares between the study areas, and study subjects. But, this result is lower than the finding from Swaziland (22.9\%) (22). The variation might be due to the difference in study subjects. In Swaziland, the study participants were all HIV positive in their status. So the occurrence of the precancerous cervical lesion in HIV cases may increase the occurrence due to the disease processes. This could be due to the disease process in which STD/HIV decreases the immune system and increase the vulnerability to cancer and other diseases.

Factors significantly associated with precancerous cervical lesion was assessed in this study. Age at first sexual intercourse has an association with the precancerous cervical lesion. Women who began early sexual intercourse $(<18)$ were 2.4 times more likely to develop precancerous cervical lesions compared to those who began sexual intercourse after 18 years old. This is consistent with studies conducted in Morocco [17], Rwanda [18], Jimma [14], Yirgalem [15], and Adama [19]. The possible reason might be due to that at an early age the reproductive organs including the cervix are not well mature, so they become more susceptible to the causative agent Human papillomavirus. Starting sex at an early age may also increase the likely hood of lifetime sexual partners and sexual activity which creates the chance of being exposed to more causative agents.

A history of sexually transmitted diseases was found to have a significant association. Women with a history of STD were about ten times more likely higher with the precancerous cervical lesion as compared to those with no history of STD. This is supported by findings done in Yirgalem [15], Swaziland [20], Morocco [17], Jimma [14], Adama [19], and Addis Ababa [21]. This association of STD and precancerous cervical lesions could be due to their common cause Human papillomavirus.

Having a husband with a history of STD was also found significantly associated with the precancerous cervical lesion. Women whose husbands had a history of STD were four times higher than to develop precancerous cervical lesions compared to those whose husbands had no history of STD. This may be due to the direct transmission of the causative agent (HPV) and other STI causing agents that aggravate the chance of occurring precancerous cervical lesions from the husband to the woman.

In this finding, the association also varies among HIV positive and negative women. Being HIV positive were eight times more likely to develop precancerous cervical lesion compared to those their HIV status was negative. This is consistent with the findings in Swaziland [20], and Yirgalem [15] but inconsistent with the study done in Jimma [14]. This may be due to the higher prevalence of HIV and low awareness and adherence to ART in the community. This could also be due to the pathological effect of HIV/AIDS on immune suppression which aggravates the chance of acquiring and transmission of HPV and other STIs.

Women who had two or more lifetime sexual partners were four times more likely to have precancerous cervical lesions compared to women who have a one-lifetime sexual partner. This is consistent with the findings in Swaziland [20], Morocco [17], Addis Ababa [21], and Yirgalem [15]. Having multiple sexual partners may increase the chance to be exposed to STD. This may lead to the increase of contact with the different causative agent subtypes and increased the occurrence precancerous cervical lesion.

\section{Limitation}

There might be social desirability bias due to the sensitive nature or cultural barrier in the community.

\section{Conclusion}

About $14 \%$ of participants had precancerous cervical lesions (positive for VIA test). Being HIV positive, having multiple sexual partners, history of STD, having a husband with a history of STD, early age initiation of sexual intercourse were significantly associated factors with the precancerous cervical lesions. Implementation of cervical cancer screening in all eligible women and enhancing community awareness on immunization of HPV and early detection and treatment of STD diseases mainly HIV/AIDS are important measures to decrease the problem.

\section{Abbreviations}

ART: Antiretroviral Therapy

HPV: Human Papilloma Virus

OCP: Oral Contraceptive Pill

SSA: Sub-Saharan Africa

STD: Sexually Transmitted Disease

STI: Sexually Transmitted Infection

VIA: Visual inspection of Acetic Acid

\section{Data Availability}

The datasets used and/or analyzed during the current study are available from the principal author upon reasonable request.

\section{Ethical Approval}

Ethical clearance was secured from Adis Ababa University Institutional Health Research Ethics Review Committee. The official letter was written to each public Hospital.

\section{Consent}

Informed written consent was obtained from each participant after explaining the purpose and benefits of the study. Respondents were informed that participating in this study is up to the willingness of them. 


\section{Conflicts of Interest}

The authors declare that they have no conflicts of interest.

\section{Authors' Contributions}

All Authors were involved in the conception and design of the study, analysis of data, interpretation of data, revising the paper. GA prepared the manuscript. All authors read and approved the final manuscript.

\section{Funding}

The funding for this research was covered by Adis Abeba University.

\section{Acknowledgements}

We would like to appreciate to Adis Abeba University for their support. Our heartfelt thanks also extend to data collectors and supervisors for their responsible data collection and support, and all the study participants for sharing their experience. Finally, we would like to thank all those who involve their motivational and material support for this work.

\section{References}

[1] Milner DA. Diagnostic Pathology: Infectious Diseases. Elsevier Health Sciences. 2015 (ISBN 9780323400374): p. 40 .

[2] Korde N KS LO. Monoclonal gammopathy of undetermined significance (MGUS) and smoldering multiple myeloma (SMM): novel biological insights and development of early treatment strategies". Blood. PMC 3316455 PMID 21441462. May 2011; 117 (21) (doi: 101182/blood-2011-01-270140): 5573-81.

[3] Kumar V AA, Fausto N, Mitchell RN. Robbins Basic Pathology (8th ed.). Saunders Elsevier. pp. 2007.

[4] Cervical Cancer Symptoms, Signs, Causes \& Survival Rates, 2018. https://www.emedicinehealth.com/cervical_cancer/article_em. htm.

[5] Baalbergen AV, Yerney; Stalpers, Lukas; Baalbergen, Astrid. "Primary surgery versus primary radiotherapy with or without chemotherapy for early adenocarcinoma of the uterine cervix". Reviews 2013.

[6] Arbyn M AA, Jordan J, Ronco G, Schenck U, Segnan N, Wiener H, Herbert A, von Karsa L. "European Guidelines for Quality Assurance in Cervical Cancer Screening. Second Edition-Summary Document". Annals of Oncology. 2010.
[8] Organization WH. "Fact sheet No. 297: Cancer". Archived from the original on 2014-02-13. February 2014.

[9] De Vuyst H, Alemany L, Lacey C, Chibwesha CJ, Sahasrabuddhe V, Banura C, et al. The burden of human papillomavirus infections and related diseases in sub-saharan Africa. Vaccine. 2013; 31 Suppl 5 (05): F32-F46.

[10] CIaMW. IARC Cancer Base GLOBOCAN. http://globocaniarcfr. 2012; 1. 0. (Available online).

[11] Jemal A BF, Forman D, O’Brien M, Ferlay J, Center M, Parkin DM.. Cancer burden in Africa and opportunities for prevention cancer. PubMed. 2012; 118 (18): 4372-84.

[12] La Vecchia C, Boccia S. Oral contraceptives, human papillomavirus and cervical cancer. Eur J Cancer Prev. 2014; 23.

[13] Ntekim A. Cervical Cancer in Sub Sahara Africa. 2012.

[14] Deksissa ZM TF, Ferede HA. Prevalence and factors associated with VIA positive result among clients screened at Family Guidance Association of Ethiopia, south west area office, Jimma model clinic, Jimma, Ethiopia 2013: a crosssectional study. BMC research notes. 2015; 8 (618).

[15] Tesfahun Hailemariam, Engidawork Mamaye, Goye Orkaido and Mihret Seta. Prevalence of Cervical Cancer and Associated Risk Factors among Women Attending Cervical Cancer Screening and Diagnosis Center at Yirgalem General Hospital, Southern Ethiopia. Journal of Cancer Science \& Therapy. 2017.

[16] Central Statistical Agency Addis Ababa E,. Demographic and Health Survey. ICF International Calverton, Maryland, USA. 2019; March 2012.

[17] Berraho M, Amarti-Riffi A, El-Mzibri M, Bezad R, Benjaafar $\mathrm{N}$, Benideer A. HPV and cofactors for invasive cervical cancer in Morocco: a multicentre case-control study. $B M C$ cancer. 2017; 17 (1): 435-45.

[18] Makuza JD NS, Muhimpundu MA, Pace LE, Ntaganira J, Riedel DJ. Prevalence and risk factors for cervical cancer and pre-cancerous lesions in Rwanda. The Pan African medical journal. 2015 (22: 26).

[19] Kassa RT. Risk factors associated with precancerous cervical lesion among women screened at Marie Stops Ethiopia, Adama town, Ethiopia 2017: a case control study. BMC research notes. 2018; 11 (1): 145.

[20] Jolly PE, Mthethwa-Hleta S, Padilla LA, Pettis J, Winston S, Akinyemiju TF, et al. Screening, prevalence, and risk factors for cervical lesions among HIV positive and HIV negative women in Swaziland. BMC public health. 2017; 17 (1): 218.

[21] Teame H, Addissie A, Ayele W, Hirpa S, Gebremariam A, Gebreheat $G$, et al. Factors associated with cervical precancerous lesions among women screened for cervical cancer in Addis Ababa, Ethiopia: A case control study. PloS one. 2018; 13 (1): $\mathrm{e} 0191506-\mathrm{e}$.

[7] WHO. WHO|Cervical cancer. 2018. 